\title{
Overlooked chronic constipation in adolescent: Hirschsprung disease
}

Semire Serin Ezer*

Department of Pediatric Surgery, Baskent University School of Medicine, Adana Teaching and Research Center, Adana, Turkey

Sir,

Hirschsprung Disease (HD) is a congenital functional gastrointestinal obstruction which is characterized by absence of intramural ganglionic cells [1]. It is most common cause of neonatal intestinal obstruction. The most effected site of the intestine is rectosigmoid region which is unable to relaxation [1]. Definitive surgical procedures aim to pull-trough the normally innervated intestinal segment to anal canal by using different surgical procedures such as Swenson, Rehbain, Soave, Boley, modified Duhamel or modified Soave (trans anal one-stage endorectal pull-through) [1]. Surgery can be performed by 1-3 staged procedure related clinical status of patients [15]. Late presentation of $\mathrm{HD}$ can be presented intractable constipation, recurrent diarrhea due to enterocolitis and growth retardation $[1,4]$. Here a delayed case which can show the importance of HD one more time when evaluating any symptoms of constipation in developing countries.

18 years of girl was presented for intractable constipation for years. Enema had been used in every 4-5 days to relief her symptoms since her birth. Sometimes cathartic agents had been used for constipation. Her weight and tall were $42 \mathrm{~kg}$ and $148 \mathrm{~cm}$ respectively that revealed growth retardation. Before admittance colonoscopy had been done and revealed nonspecific mucosal inflammation in another center that had not solved her clinical chart. Physical examination revealed distended abdomen and digital rectal examination revealed empty rectal ampulla and hypertonic anal sphincter tonus. Erect abdominal radiogram showed gas and fecal retention with distended abdomen (Figure 1). HD was suspected according to her history of necessity of enema frequently. Barium enema revealed narrowed rectum and transitional zone in sigmoid colon with distended remained all proximal colonic segments until cecum. Three staged surgery was planned because of chronic mucosal inflammation and dilated diameter of colon that was resulted from enterocolitis. Surgery revealed dilated colon with narrow recto-sigmoid region. Entire colon had severely thickened wall. Intraoperative frozen section biopsy was revealed no ganglion cells at the narrow rectosigmoid region. Proximal of this region histopathology revealed ganglionic zone. So, end sigmoid colostomy was performed at the middle site of sigmoid colon. Her weigh was reached to $54 \mathrm{~kg}$ in 4 months period following colostomy. Then definitive surgery was done by using Swenson procedure (low anterior resection with colorectal anastomosis) with protective ileostomy. Two months later ileostomy was broken down. Three staged operative courses

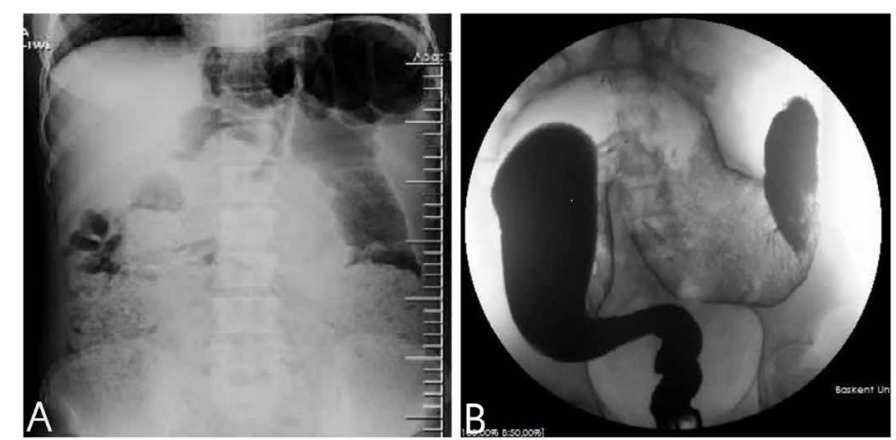

Figure 1. (A) Erect abdominal radiogram showing dilated colonic segments by stool and gasses; (B) Barium enema revealing the narrowed proximal rectum with transitional zone to the sigmoid colon and proximal dilated descending colonic segments

were uneventful. Post-operative follows were uneventful with 1-3 defecation in a day.

I aimed to emphasize my sadness of delaying in diagnosis which should be easily diagnosed by questioning detailed meconium discharge in newborn period and stooling habits in childhood. Unfortunately, we have still read delayed diagnosis HD in the literature [2-5]. Some surgical procedures are reported in the world with different complications. The surgeon should be plan proper surgical technique according the clinical status of patients.

Here the imported point is Hirschsprung disease may be overlooked easily when dealing with intractable constipation in late childhood. It should be state in mind before treated refractory constipation in all ages. Clinicians should meticulously analyze detailed history and remarkable diagnostic tests for intractable constipation.

\section{References}

1. Langer JC (2012) Hirschsprung disease. In Arnold G. Coran (eds), Pediatric Surgery (seventh edition), New York, pp: 1265-1278.

2. Qiu JF, Shi YJ, Hu L, Fang L, Wang HF, et al. (2013) Adult Hirschsprung's disease: Report of four cases. Int J Clin Exp Pathol 6: 1624-1630. [Crossref]

3. Bakari AA, Gali BM, Ibrahim AG, Nggada HA, Ali N, et al. (2011) Congenital aganglionic megacolon in Nigerian adults: two case reports and review of the literature. Niger J ClinPract 14: 249-252.

*Correspondence to: Semire Serin Ezer, Baskent University School of Medicine, Adana Teaching and Research Center, Adana, Turkey, Tel: 905332583929, Fax: 903223271279, E-mail: semireserin@yahoo.com

Received: January 16, 2019; Accepted: January 25, 2019; Published: January 28 2019 
4. Martins MR, Marquesdos Santos CH, Falcão GR (2015) Late diagnosis of Hirschsprung's disease. J Coloproct 35: 178-181.
5. Nakatake R, Hamada Y, Miki H, Shirai T, Nakamura Y, et al. (2016) A case of Hirschsprung's disease underwent surgery in adulthood. J PedSurg Case Reports 13: 1e5.

Copyright: (2019 Ezer SS. This is an open-access article distributed under the terms of the Creative Commons Attribution License, which permits unrestricted use, distribution, and reproduction in any medium, provided the original author and source are credited. 